\title{
ASPECTOS DA BIOLOGIA DAS ESPÉCIES CAPTURADAS POR ESPINHEL PELÁGICO NA REGIÃO SUL DAS ILHAS DE TRINDADE E MARTIN VAZ NO VERÃO DE 2001
}

\author{
MAZZOLENI, R.C. \& P.R. SCHWINGEL \\ CTTMar/UNIVALI - Rua Uruguai, 458. CEP 88302-202, Itajaí - SC, Brasil \\ E-mail: rmazzoleni@cttmar.univali.br, schwingel@cttmar.univali.br
}

\section{RESUMO}

\begin{abstract}
O presente trabalho descreve aspectos da biologia das espécies capturadas com espinhel pelágico na região sul das ilhas de Trindade e Martin Vaz, entre $22^{\circ} \mathrm{S}-26^{\circ} \mathrm{W}$ a $25^{\circ} \mathrm{S}-40^{\circ} \mathrm{W}$. Dados sobre reprodução e alimentação das espécies são analisados.
\end{abstract}

Palavras-Chaves: espinhel pelágico, Trindade, Martin Vaz, Brasil.

\begin{abstract}
BIOLOGICAL ASPECTS OF PELAGIC LONGLINE CAUGHT SPECIES IN SOUTH REGION OF TRINDADE AND MARTIN VAZ ISLANDS IN SUMMER OF 2001
\end{abstract}

\begin{abstract}
The present work describe biological aspects of species captured with pelagic longline in south regions of Trindade and Martin Vaz islands, between $22 \div \mathrm{S}-26^{\circ} \mathrm{W}$ to $25^{\circ} \mathrm{S}-40^{\circ} \mathrm{W}$. Data about reproduction and feeding ecology of different species are analised.
\end{abstract}

Keywords: pelagic longline, Trindade, Martin Vaz, Brazil.

\section{INTRODUÇÃO}

A pesca com espinhel pelágico no Brasil teve início na região nordeste na década de 1950. A frota era composta por barcos estrangeiros arrendados e tinham como espécies-alvo os atuns. No início da década de 1960, os espinheleiros passaram a operar com base no porto de Santos (SP), empregando um esforço de 500.000 anzóis/ano no período de 1964 a 1972 (Zavala-Camin \& Tomás, 1990). Atualmente, a frota nacional e arrendada divide-se entre os portos de Cabedelo, Natal, Recife, Santos, Itajaí e Rio Grande.

Em Itajaí, a frota espinheleira compreende cerca de 16 embarcações nacionais direcionadas principalmente à pesca do espadarte (meka) Xiphias gladius. Essa frota ca- racteriza-se pela pouca profundidade de operação do petrecho $(50 \mathrm{~m})$, uso de linha madre com cabos secundários de poliamida monofilamento (sistema norte-americano).

Atualmente o Brasil possui uma nova política de expansão e ocupação pesqueira em sua ZEE e em águas internacionais, a qual está associada a captura de diferentes espécies, que freqüentemente são compartilhadas com outros países. Neste contexto, é necessário conhecermos melhor as espécies que compõe essa pescaria para chegarmos a medidas adequadas de manejo pesqueiro. Assim, o presente trabalho visa ampliar o conhecimento desta pescaria no que se refere a aspectos da biologia das espécies capturadas por espinhel pelágico na região Sul das Ilhas de Trindade e Martin Vaz. 


\section{MATERIAIS E MÉTODOS}

Entre 4 e 26 de Janeiro de 2001, realizou-se uma viagem com o espinheleiro Yamaya III, da empresa Kowalsky Ind. e Com. de Pescados Ltda. A área de pesca situou-se entre os $22^{\circ} \mathrm{S}-26^{\circ} \mathrm{W}$ a $25^{\circ} \mathrm{S}-35^{\circ} \mathrm{W}$, a sul da cadeia Vitória-Trindade (Figura 1).

$\mathrm{Na}$ viagem, realizaram-se 13 lances, com média de 1.100 anzóis/lance. A dinâmica do petrecho constituía-se em: lançamento, das $18 \mathrm{~h}$ às $24 \mathrm{~h}$; tempo de pesca, variável devido a tarefa de recolhimento; e recolhimento, começando às $5 \mathrm{~h}$, podendo estender-se até às $11 \mathrm{~h}$ ou mesmo até às $14 \mathrm{~h}$.

Os indivíduos capturados foram identificados, mensurados, sexados e os estádios de maturação determinados. Dos elasmobrânquios obteve-se também o número de embriões presentes em cada fêmea e a presença ou não de esperma nos machos. As medidas obtidas para os elasmobrânquios foram: comprimento total (CT), comprimento furcal (CF), comprimento inter-dorsal (CID) e largura de disco (LD); e para os teleósteos: comprimento total (CT), comprimento furcal (CF) e comprimento maxila-furca (CMF).

Para avaliação dos hábitos alimentares, analisou-se o conteúdo estomacal identificando-se as presas até o menor taxa possível. $O$ grau de repleção estomacal por análise visual e a freqüência de ocorrência de cada presa foram registrados. Para a determinação dos estágios de maturação gonadal dos teleósteos, utilizou-se a classificação proposta por Vazzoler (1996).

\section{RESULTADOS E DISCUSSÃO}

As capturas foram compostas por 5 espécies de elasmobrânquios e 9 de teleósteos (Tabela 1).

Das quatorze espécies capturadas três foram mais ocorrentes (i. e. o tubarão azul, a raia e o espadarte), sendo apresentadas a seguir:

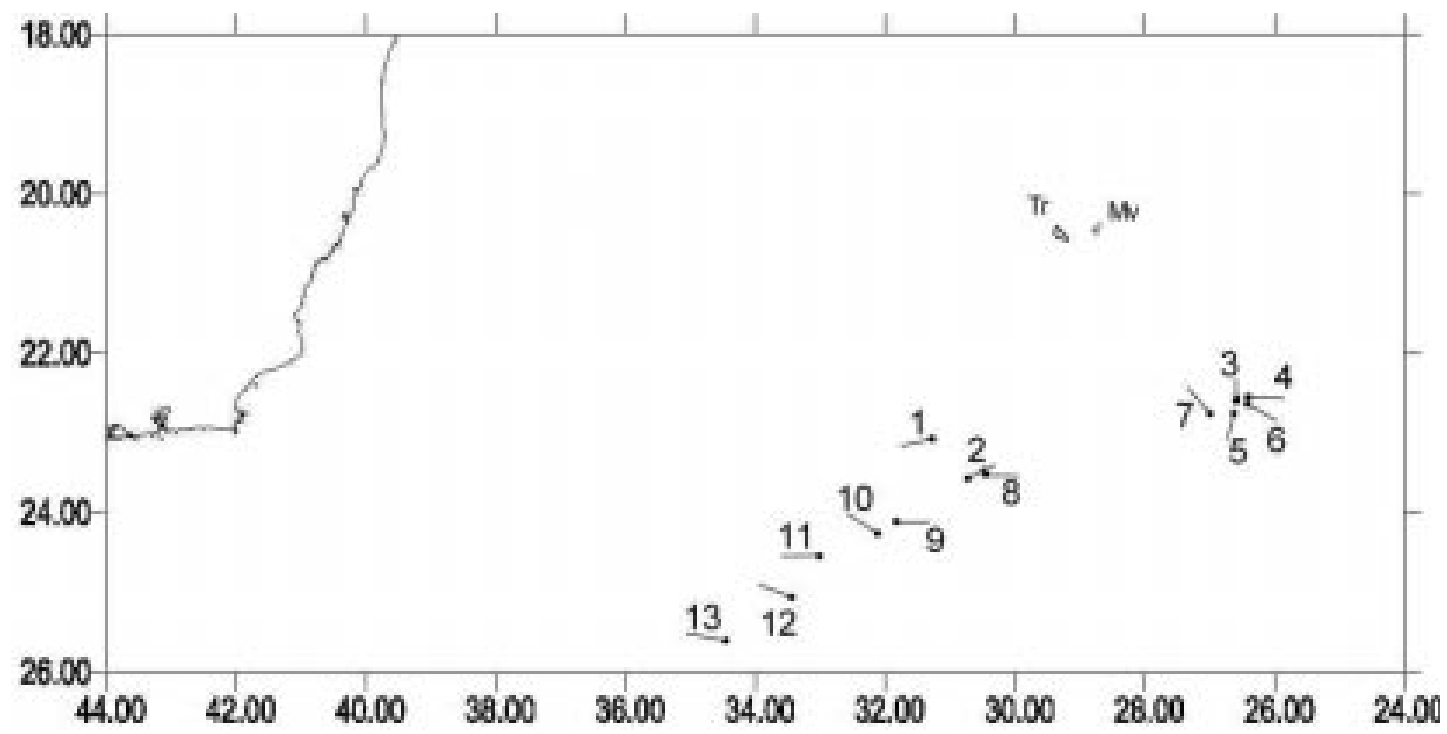

Figura 1: Localização dos lances realizados em janeiro de 2001. Nota: $\mathrm{Tr}$ - Ilha de Trindade; MV - Arquipélago de Martin Vaz; o ponto na extremidade das retas indica o início do lance. As ilhas tiveram seu tamanho exagerado aproximadamente 150x. 
Tabela 1: Espécies e número de exemplares capturados na área de estudo em janeiro de 2001.

\begin{tabular}{|c|c|c|}
\hline \multicolumn{2}{|c|}{ Espécies } & \multirow{2}{*}{$\begin{array}{l}\text { Captura } \\
\text { total }(\mathrm{n})\end{array}$} \\
\hline Nome vulgar & Nome científico & \\
\hline Anequim & Isurus oxyrinchus & 2 \\
\hline Galha branca & $\begin{array}{l}\text { Carcharhinus } \\
\text { longimanus }\end{array}$ & 5 \\
\hline Vaca & Sphyrna lewini & 1 \\
\hline Cação azul & Prionace glauca & 104 \\
\hline Raia & Pteroplatytrygon violacea & 48 \\
\hline Peixe prego & $\begin{array}{l}\text { Lepidocybium } \\
\text { flavobrunneum }\end{array}$ & 20 \\
\hline Espada preta & Gempylus serpens & 5 \\
\hline Dourado & Coryphaena hippurus & 14 \\
\hline Maka & Tetrapturus albidus & 2 \\
\hline Agulhão negro & Makaira nigricans & 4 \\
\hline Espadarte & Xiphias gladius & 116 \\
\hline Cavala & Acanthocybium solandri & 2 \\
\hline Albacora branca & Thunnus alalunga & 4 \\
\hline $\begin{array}{l}\text { Albacora } \\
\text { bandolim }\end{array}$ & Thunnus obesus & 1 \\
\hline
\end{tabular}

\section{Tubarão azul - Prionace glauca (Linnaeus, 1758)}

Foi o elasmobrânquio mais capturado no cruzeiro $(n=104)$. A maior concentração da captura de $P$. glauca ocorreu nos três últimos lances (11 a 13), quando a pesca se realizou mais ao sul (Figura 1). A amplitude de comprimentos para as fêmeas variou de $175 \mathrm{~cm}$ a $284 \mathrm{~cm}$, enquanto que para os machos foi de $140 \mathrm{~cm}$ a $302 \mathrm{~cm}$. Observou-se nas distribuições de comprimento que os exemplares maiores que $260 \mathrm{~cm}$ foram representados em sua maior parte por machos (Figura 2).

Dados biométricos foram obtidos para possibilitar futuras investigações utilizando amostragem de desembarques na pesca industrial, onde os indivíduos são descarregados já eviscerados e sem cabeça. Para tanto, estimou-se a relação CT e CID para machos e fêmeas separadamente (Figura 3).

A relação macho/fêmea obtida foi de 1,08. Em 15 fêmeas analisadas (39,4\%) houve a presença de marcas de cópula em diferentes graus de cicatrização. Analisando o aparelho reprodutor das fêmeas, 4 (10,5\%) possuíam ovócitos nos ovários e 32 (84,2\%) estavam em estágio inicial de gravidez, com seus ovócitos fecundados e em fase de implantação nos úte-
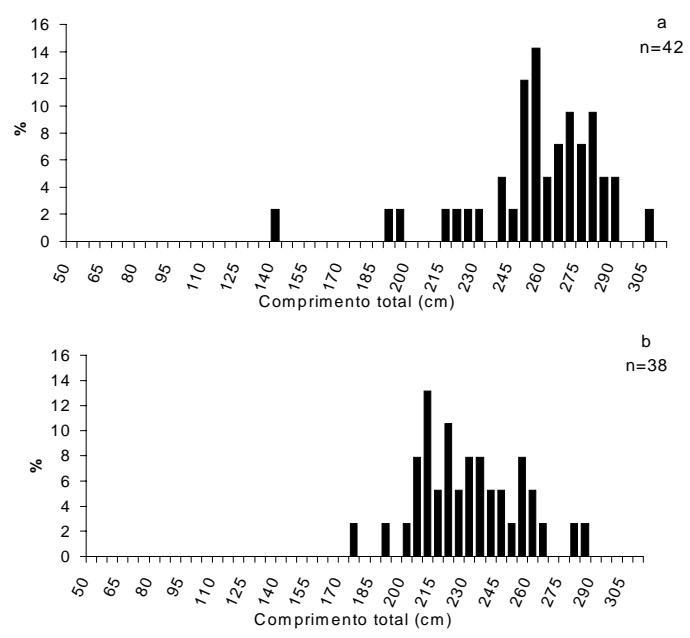

Figura 2: Distribuição de freqüência de comprimentos para machos (a) e fêmeas (b) de P. glauca.

ros. A fecundidade foi estimada para 11 fêmeas (Figura 4), encontrando-se uma média de 51,5 ovócitos por fêmea. A menor fêmea grávida encontrada possuía $200 \mathrm{~cm}$, valor que fica próximo a estimativa de maturidade encontrada por Pratt (1979) que é de $185 \mathrm{~cm}$ para as fêmeas. O menor macho maduro encontrado possuía $195 \mathrm{~cm}$, o que também está a cerca da estimativa de Pratt (op. cit.) que foi $180 \mathrm{~cm}$. Os dados também revelaram uma aparente relação positiva entre o número de embriões e o comprimento da fêmea, o que indica que fêmeas maiores possuem um maior número de embriões (Figura 4).

Com referencia a repleção estomacal do tubarão azul, verificou-se que a maior parte dos indivíduos analisados mostraram a dominância dos graus de repleção 1 e 3 , sendo que a porcentagem de estômagos vazios foi baixa (Tabela 2). A dieta foi composta, predominantemente por cefalópodes e teleósteos (Tabela 3). Dentre as presas identificadas, o baiacú de espinhos Diodon histix (Linnaeus, 1758) ocorreu em $30 \%(n=6)$ dos estômagos analisados e em todos estes apresentou-se em estágio inicial de digestão. Segundo Gasparine \& 


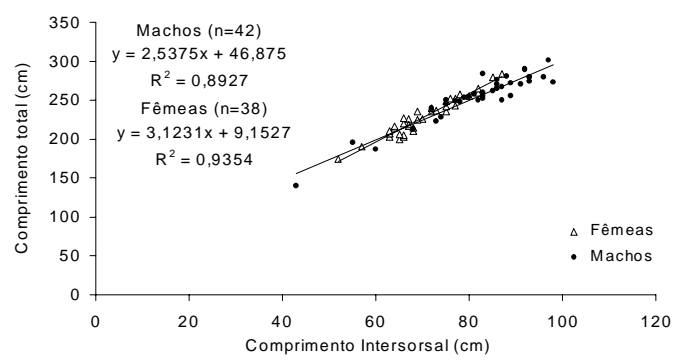

Figura 3: Relação entre CT e CID para os machos e fêmeas de $P$. glauca.

Floeter (2001) este teleósteo é comum na região de entorno da llha de Trindade até os $20 \mathrm{~m}$ de profundidade e conhecido por ter hábitos demersais relacionados a uma alimentação bentônica. O que indica que o tubarão azul usa a região de entorno das ilhas como uma área de alimentação.

\section{Raia Pelágica - Pteroplatytrygon violacea (Bonaparte, 1832)}

Um total de 48 exemplares, entre 30 e $66 \mathrm{~cm}$ LD foram capturados. (Figura 5). Na distribuição de freqüência ficou evidenciado que as fêmeas alcançaram tamanhos maiores que os machos nas capturas

A relação macho/fêmea foi de 0,45 , o que não demonstra uma maior utilização da área pelas fêmeas. Entretanto o maior número destas nas capturas pode ser efeito da mortalidade causada nos machos em decorrência de ferimentos causados pelo espinho da fêmea no momento da cópula (com. pes. Henry Mollet, Monterey Bay Aquarium, Monterey, California).

Em 15 fêmeas analisadas de $P$. violacea, 11 encontravam-se grávidas com uma média de 5,4 embriões/fêmea possuindo tamanhos superiores a $50 \mathrm{~cm}$ LD. A Figura 6 mostra a fecundidade obtida para esses exemplares, bem como sugere que os indivíduos maiores possuam um maior número de embriões.

A análise do conteúdo estomacal de 24 exemplares, mostrou que a maioria dos exemplares analisados não havia ingerido alimento

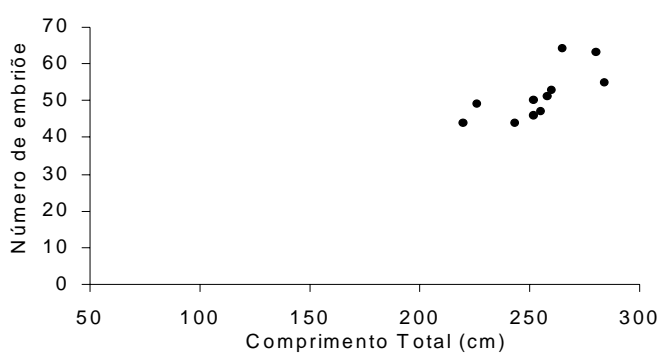

Figura 4: Fecundidade observada para fêmeas de $P$. glauca.

ou que este existia em pouca quantidade (Tabela 2). A dieta desta raia foi representada principalmente por cefalópodes e crustáceos, com pouca presença de teleósteos (Tabela 3).

\section{Espadarte - Xiphias gladius Linnaeus, 1758}

Durante o cruzeiro, 116 indivíduos da espécie-alvo da pescaria, Xiphias gladius foram capturados. A distribuição de freqüência dos espadartes capturados é mostrada na Figura 7, revelando a dominância de indivíduos entre 130 à 200 cm CMF. Segundo Arfelli (1996) isto representa exemplares com idades entre 1 a 10 anos. Nesta mesma distribuição pode-

Tabela 2: Porcentagem dos graus de repleção estomacal observados para cada espécie componente da captura. Nota: $0=$ vazio, $1=25 \%$ cheio, $2=50 \%$ cheio, $3=$ $75 \%$ cheio, $4=$ cheio.

\begin{tabular}{lcccccc}
\hline \hline \multirow{2}{*}{ Espécie } & $\begin{array}{c}\text { Exemplares } \\
\text { analisados }\end{array}$ & \multicolumn{5}{c}{ Grau de repleção } \\
\cline { 3 - 7 } & $(\mathrm{n})$ & 0 & 1 & 2 & 3 & 4 \\
\hline Anequim & 1 & - & - & - & 100 & - \\
Galha branca & 5 & 20,0 & 20,0 & 40,0 & 20,0 & - \\
Vaca & 1 & - & - & - & - & 100 \\
Cação azul & 23 & 13,0 & 30,4 & 17,3 & 34,7 & 4,3 \\
Raia & 24 & 29,1 & 29,1 & 16,6 & 8,3 & 12,5 \\
Peixe prego & 6 & 100 & - & - & - & - \\
Espada preta & 2 & - & 50,0 & - & 50,0 & - \\
Dourado & 0 & - & - & - & - & - \\
Maka & 2 & - & - & 100 & - & - \\
Agulhão negro & 2 & 50,0 & - & - & 50,0 & - \\
Espadarte & 24 & 54,1 & 16,6 & 16,6 & 8,3 & \\
Cavala & 0 & - & - & - & - & - \\
Albacora branca & 0 & - & - & - & - & - \\
Albacora & 0 & - & - & - & - & - \\
bandolim & & & & & & \\
\hline \hline
\end{tabular}


Tabela 3: Freqüência de ocorrência das presas encontradas no conteúdo estomacal das espécies analisadas no cruzeiro.

\begin{tabular}{|c|c|c|c|c|c|c|c|}
\hline \multirow{2}{*}{ Espécie } & \multirow{2}{*}{$\begin{array}{l}\text { Estômagos } \\
\text { com } \\
\text { conteúdo } \\
\text { (n) }\end{array}$} & \multicolumn{6}{|c|}{ Itens alimentares } \\
\hline & & ovos & Crustáceos & Cefalópodes & Elasmobrânquios & Teleósteos & Mamíferos \\
\hline Anequim & 1 & - & - & - & - & 100 & - \\
\hline Galha branca & 4 & - & - & 50,0 & - & 75,0 & - \\
\hline Vaca & 1 & - & - & - & - & - & 100 \\
\hline Cação azul & 20 & 10,0 & - & 70,0 & 20,0 & 65,0 & - \\
\hline Raia & 17 & - & 100,0 & 60,0 & - & 13,3 & - \\
\hline Peixe prego & 0 & - & - & - & - & - & - \\
\hline Espada preta & 2 & - & - & 50,0 & - & 100 & - \\
\hline Dourado & 0 & - & - & - & - & - & - \\
\hline Maka & 2 & - & - & 100 & - & 50,0 & - \\
\hline $\begin{array}{l}\text { Agulhão } \\
\text { negro }\end{array}$ & 1 & - & - & 50,0 & - & 50,0 & - \\
\hline Espadarte & 11 & - & - & 90,9 & - & 45,4 & - \\
\hline Cavala & 0 & - & - & - & - & - & - \\
\hline $\begin{array}{l}\text { Albacora } \\
\text { branca }\end{array}$ & 0 & - & - & - & - & - & - \\
\hline $\begin{array}{l}\text { Albacora } \\
\text { bandolim }\end{array}$ & 0 & - & - & - & - & - & - \\
\hline
\end{tabular}
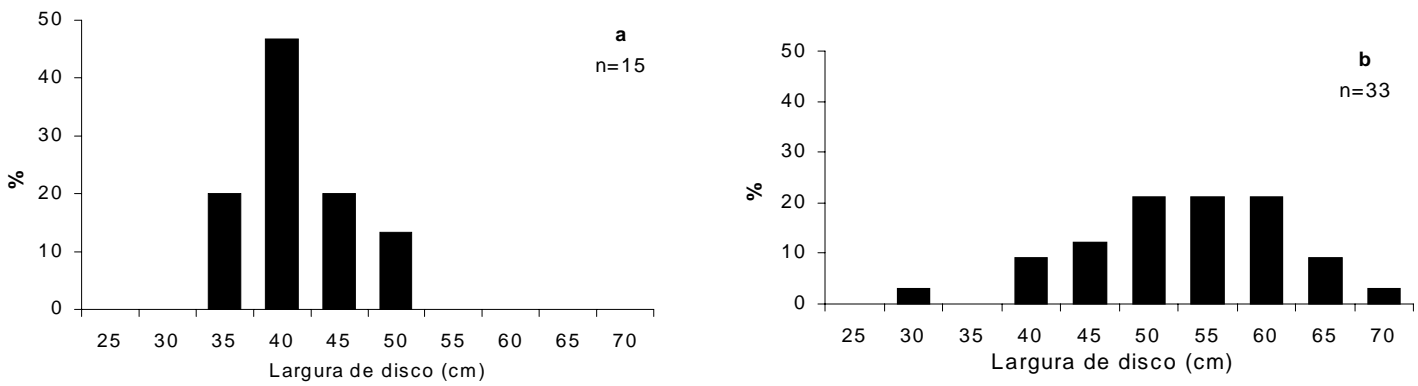

Fig. 5: Distribuição de freqüência para machos (a) e fêmeas

(b) de P. violacea capturados na viagem.

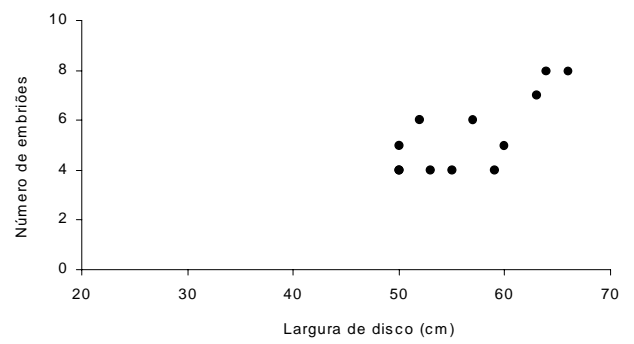

Figura 6: Fecundidade observada para as fêmeas de $P$. violacea. mos identificar ainda diferentes modas, com destaque à uma pequena moda entre $90 \mathrm{e}$ $100 \mathrm{~cm}$ associada a indivíduos juvenis menores que 2 anos de idade segundo o mesmo autor

Buscando-se uma ferramenta de auxílio para os estudos biológicos-pesqueiros, onde 0 CMF é a medida padrão, apresentamos na Figura 8 a relação entre essa medida e o comprimento inter-dorsal (CID), que freqüentemente é a única medida possível em amostragens de esembarques. 


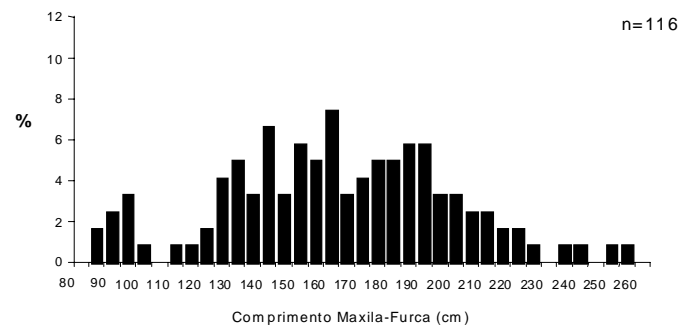

Figura 7: Distribuição de freqüência de comprimentos para os exemplares de $X$. gladius capturados no cruzeiro.

As Tabelas 2 e 3 mostram que os estômagos vazios foram dominantes para o espadarte. Entretanto, os estômagos analisados com conteúdo revelaram a predominância de cefalópodes.

Nos exemplares que tiveram suas gônadas analisadas, identificou-se 3 machos e 15 fêmeas. Todos os machos (193 - 194cm CMF) eram indivíduos no estágio maduro. As 15 fêmeas analisadas apresentaram comprimentos (CMF) superiores a $196 \mathrm{~cm}$, sendo que em 9 (60\%) os ovários apresentaram-se com uma intensa rede capilar que segundo Vazzoler (1996) é característica de um estádio gonadal que apresenta-se em maturação. As outras 6 fêmeas (40\%) apresentavam-se com gônadas maduras.

No decorrer do cruzeiro, foram capturadas mais três espécies de elasmobrânquios e sete espécies de teleósteos, porém pouco frequentes. Os dados obtidos quanto a amplitude de tamanho e alimentação das mesmas encontram-se listados nas Tabelas 2, 3 e 4.

Os dados obtidos no presente estudo permitem uma primeira visão sobre a biologia das espécies na área analisada. Estes resultados indicam que a área de estudo é utilizada pela raia pelágica Pteroplatytrigon violacea, o espadarte Xiphias gladius e o tubarão azul Prionace glauca em seus ciclos de vida para atividades relacionadas à reprodução. Além disso, fica claro um relacionamento entre o tubarão azul e o ambiente insular da Cadeia Vi-

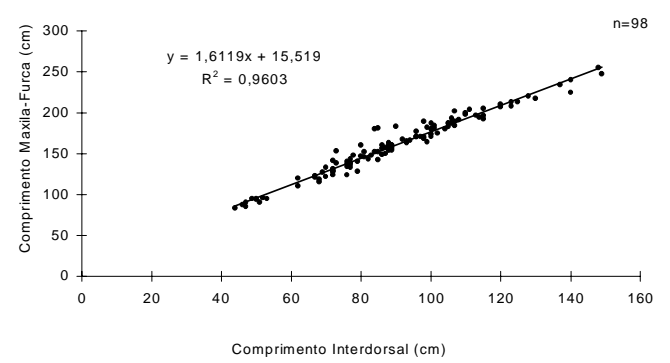

Figura 8: Relação obtida entre o CMF e CID para os exemplares de $X$. gladius.

tória-Trindade, onde pode utilizar as ilhas para a obtenção de alimento. Em um estudo realizado na região Nordeste do Brasil, Vaske Jr. (2000) encontrou estas mesmas espécies na área oceânica aos arredores dos Arquipélagos de São Pedro e São Paulo, Fernando de Noronha e Atol das Rocas em padrões similares de utilização de recursos alimentares. Entretanto, para a área do presente estudo, a diversidade de presas apresentou-se menor que a de Vaske Jr. (op. cit.) para as mesmas espécies de predadores analisadas.

Tabela 4: Amplitude de tamanho (cm) obtidos das demais espécies de teleósteos capturadas no cruzeiro.

\begin{tabular}{lccc}
\hline \hline \multicolumn{1}{c}{ Espécies } & $\begin{array}{c}\text { Captura } \\
\text { total }(\mathrm{n})\end{array}$ & $\begin{array}{c}\text { Exemplares } \\
\text { medidos }(\mathrm{n})\end{array}$ & $\begin{array}{c}\text { Amplitude } \\
\text { de } \\
\text { Tamanho } \\
(\mathrm{cm})\end{array}$ \\
\hline Anequim & 2 & 2 & $210-227$ \\
Galha branca & 5 & 5 & $116-182$ \\
Vaca & 1 & 1 & 292 \\
Espada preta & 5 & 1 & 120 \\
Dourado & 14 & - & - \\
Peixe prego & 20 & 20 & $48-156$ \\
Agulhão branco & 2 & - & - \\
Agulhão negro & 4 & 2 & $252-307$ \\
Cavala & 2 & 1 & 141 \\
Albacora & 4 & 3 & $107-118$ \\
branca & & & 151 \\
Albacora & 1 & 1 & \\
bandolim & & & \\
\hline \hline
\end{tabular}




\section{REFERÊNCIAS BIBLIOGRÁFICAS}

Arfelli, C.A. 1996. Estudo da pesca e aspectos da dinâmica populacional de espadarte, Xiphias gladius L. 1758, no Atlântico Sul. Tese de doutorado, UNESP.

Gasparini, J.L. \& S.R. Floeter. 2001. The shore fishes of Trindade Island, western South Atlantic. Journal of Natural History, 35: 1639-1656.

Pratt Jr., H.L. 1979. Reproduction in the blue shark, Prionace glauca. Fish. Bull. 77(2): 445-470.
Vaske Jr., T. 2000. Relações tróficas dos grandes peixes pelágicos da região equatorial sudoeste do Oceano Atlântico. Tese doutorado, FURG.

Vazzoler, A.E. A.M. 1996. Biologia da reprodução de peixes teleósteos: teoria e prática. Ed. EDUEM.

Zavala-Camim, L.A. \& A.R.G. Tomás. 1990. A pesca de atuns com espinhel no Atlântico Sudoeste por barcos japoneses e brasileiros (1959-1979). B. Inst. Pesca, 17: 6175. 